Staff Working Paper/Document de travail du personnel 2019-3

\title{
Can Capital Deepening Explain the Global Decline in Labor's Share?
}

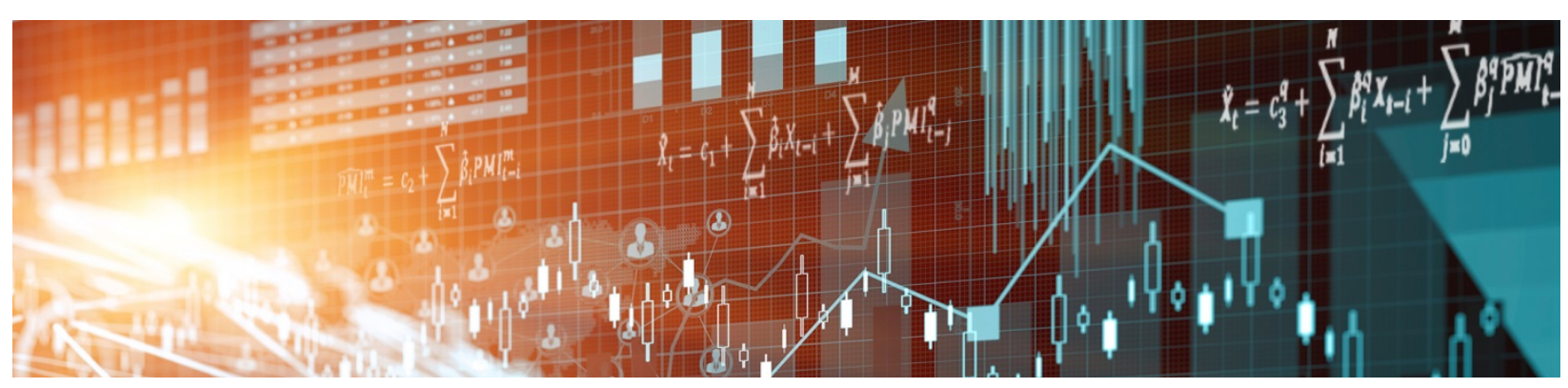

by Andrew Glover and Jacob Short 
Bank of Canada Staff Working Paper 2019-3

January 2019

\title{
Can Capital Deepening Explain the Global Decline in Labor's Share?
}

by

\author{
Andrew Glover ${ }^{1}$ and Jacob Short ${ }^{2}$ \\ 1 Department of Economics \\ University of Texas at Austin \\ Austin, Texas, USA 78722 \\ andrew.glover@austin.utexas.edu \\ 2 Financial Stability Department \\ Bank of Canada \\ Ottawa, Ontario, Canada K1A 0G9 \\ jshort@bankofcanada.ca
}




\section{Acknowledgements}

We are deeply grateful to Justin Barnette, Rui Castro, Oli Coibion, Jonathan Heathcote, Igor Livshits, Lance Lochner, Jim Macgee, Salvador Navarro, Erwan Quintin, David Rivers, and José-Víctor Ríos-Rull for helpful discussion and advice on earlier drafts of this paper. We thank Loukas Karabarbounis and Brent Neiman for making their data on labor's share and investment prices public. Any errors are our own. 


\begin{abstract}
We estimate an aggregate elasticity of substitution between capital and labor near or below one, which implies that capital deepening cannot explain the global decline in labor's share. Our methodology derives from transition paths in the neo-classical growth model. The elasticity of substitution is identified from the cross-country correlation between trends in the labor share and (a proxy for) the rental rate of capital. Trends in labor's share and the rental rate are weakly correlated across countries, and inversely related in most samples. Previous cross-country estimates of this elasticity were substantially greater than one, which we show was partly due to omitted variable bias: earlier studies used investment prices alone to proxy for the rental rate, whereas the growth model relates rental rates to investment prices and consumption growth.
\end{abstract}

Bank topics: International topics; Firm dynamics; Labour markets

JEL codes: E25, E22, J3, E13

\title{
Résumé
}

Nous estimons une élasticité de substitution agrégée entre le capital et le travail qui est près de ou inférieure à l'unité, ce qui signifie que l'intensification du capital ne peut pas expliquer la baisse de la part du revenu attribuable au travail observée à l'échelle mondiale. Notre méthode provient des sentiers de transition du modèle de croissance néoclassique. L'élasticité de substitution est déterminée à partir de la corrélation entre les tendances de la part du revenu attribuable au travail et du coût de location du capital (exprimé par une variable d'approximation) pour divers pays. Ces tendances sont faiblement corrélées entre les pays et négativement corrélées dans la plupart des échantillons. Les estimations précédentes de cette élasticité étaient nettement supérieures à l'unité, résultat qui découle en partie d'un biais dû à l'omission de variables : nous montrons en effet que les études antérieures n'utilisaient que le prix de l'investissement comme variable d'approximation du coût de location du capital. Or le modèle de croissance établit un lien entre le coût de location, le prix des investissements et la croissance de la consommation.

Sujets : Questions internationales; Dynamique des entreprises; Marchés du travail Codes JEL : E25, E22, J3, E13 


\section{Non-Technical Summary}

The share of total income paid to workers (labor's share) has been declining globally over the past 30 years. Understanding this decline is important for two reasons: first, prior to 1975, labor's share was relatively constant, and many of the assumptions in modern macroeconomic theories are tied to this constancy. Second, a fall in labor's share may have important implications for income and wealth inequality, which has been rising over the same period of time.

A potential explanation of the decline in labor's share is that, due to a fall in the price of investment goods, countries accumulate greater amounts of capital inputs relative to labor inputs. If capital and labor are substitutes in the production of final goods, then this capital deepening can lead to a rise in the share of income paid as returns on capital and a fall in labor's share. The degree of substitutability between capital and labor is pivotal. If capital and labor inputs are complementary inputs in production, then greater accumulation of capital would lead to a rise in labor's share. This potential explanation has renewed macroeconomists' interest in estimating the aggregate elasticity of substitution between capital and labor.

Using the theory of capital demand of a profit-maximizing firm and cross-country data, we estimate the elasticity of substitution from the correlation between countryspecific trends in rental rates of capital and labor's share. We find that a unitary aggregate elasticity of substitution between capital and labor is consistent with crosscountry data. This implies that capital and labor are not gross substitutes in production, and that capital deepening cannot explain the decline in labor's share. Furthermore, we show that previous estimates using cross-country data are biased upwards (concluding capital and labor are substitutes) because they omitted a theoretically and empirically important variable related to consumption growth. Importantly, our finding reconciles the previous cross-country evidence with the existing literature using firm-level data, the bulk of which estimate that capital and labor are not substitutes. 


\section{Introduction}

Historically, Kaldor's stylized facts have supported a unitary elasticity of substitution between capital and labor due to the near constancy of labor's share of income (Kaldor (1957)). As documented by Karabarbounis and Neiman (2014), this near constancy is no more - labor's share has declined globally since the 1980s. This downward trend, which has occurred alongside rising income and wealth inequality (Piketty (2014), Piketty and Zucman (2014)), has renewed macroeconomists' interest in estimating the aggregate elasticity of substitution between capital and labor (henceforth referenced as $\sigma \geq 0$ ). This parameter is pivotal: if it is smaller (greater) than 1 then anything that causes an increase in the capital-labor ratio will increase (reduce) labor's share. Specifically, if it is significantly larger than 1 , then the global decline in labor's share can be explained by capital deepening due to falling investment prices, as observed over the same time period. Using a large cross section of countries, we estimate that $\sigma \leq 1$ and conclude that capital deepening cannot account for the global decline in labor's share.

We identify $\sigma$ from the capital demand function of a profit-maximizing firm in the neo-classical growth model. This demand function implies that a $1 \%$ fall in the rental rate of capital should reduce labor's share of income by $(\sigma-1) \%$. The idea of the cross-country estimation strategy is to correlate country-specific trends in rental rates and labor's share to estimate $\sigma$. Unfortunately, rental rates are not readily available for a large cross section of countries, so we use the inter-temporal Euler equation for investment to find a proxy. This condition implies that the rental rate depends on the relative price of investment goods, as well as a transitional term that reflects the gradual rise in consumption in response to lower investment prices. We estimate $\sigma$ from various data sources, cross-sectional samples of countries, and statistical models. Our estimates are typically smaller than one (although statistically indistinguishable). The average point estimate from our baseline specification is $\hat{\sigma}=0.973$, which implies that the global decline in investment prices should have increased labor's share slightly.

Our results contrast sharply with two recent studies by Karabarbounis and Neiman (2014) (henceforth KN) and the International Monetary Fund World Economic Outlook (2017) (henceforth IMF). These studies also estimate $\sigma$ from cross-country correlations between trends in labor's share and investment prices, but omit consumption growth and assume that trends in the rental rate are identical to trends in investment prices. ${ }^{1}$

\footnotetext{
${ }^{1}$ At least one earlier study estimates $\sigma$ from cross-country data and finds a similar result to ours. Backus, Henriksen and Storesletten (2008) use cross-country variation in corporate tax rates and capitaloutput ratios to estimate $\sigma \approx 1$. Their conclusion, which our estimates reaffirm, is that cross-country
} 
For example, KN estimate $\sigma \approx 1.26$ and conclude that capital deepening due to falling investment prices can account for half of the global decline in labor's share. Similarly, the IMF estimates that developed countries have an elasticity greater than one (although they do estimate that emerging-market countries have an elasticity less than one). We provide a full account of why our estimates differ from these studies in Section 6.

Our chief conceptual innovation relative to the KN/IMF studies is to proxy for rental rates using their theoretical relationship with investment prices and consumption rather than investment prices alone. While investment prices are a valid proxy for rental rates in a steady state (i.e., after investment prices have been constant for a long time), the data are clearly inconsistent with such an assumption: both consumption and investment prices exhibit trends that are significantly different from zero on average and vary substantially across countries. Our proxy, which includes a transitional term reflecting consumption growth, is valid along transition paths. We show, both theoretically and empirically, that omitting the transitional term can substantially bias estimates of $\sigma$ away from one. ${ }^{2}$ Using our proxy for the rental rate reduces the absolute effect of investment prices on labor's share of income, as mediated by rental rates, by more than $50 \%$ in cases and often reduces the effect to zero, both in terms of statistical significance and economic magnitude.

Section 2.1 provides a theoretical basis for our rental rate proxy and the omitted variable bias from excluding it, but a simple example provides intuition. Suppose that $\sigma$ is slightly above one ${ }^{3}$ and the relative price of investment follows a path of geometric decline, eventually falling by $1 \%$ (i.e., the investment price falls by half of the remaining distance each year). Households choose a smooth path of consumption to the new steady state, along which consumption growth is declining, which causes rental rates to transition slower than investment prices. The path of consumption implies a slow rise in the investment rate and gradual capital deepening. An econometrician whose data start late in the transition will observe an essentially flat path for the investment price but a downward trend in labor's share. If the econometrician ignores the trend in consumption growth, they will underestimate the decline in rental rates and erroneously infer a large value of $\sigma{ }^{4}$

The above intuition aligns with our empirical results. Estimates of $\sigma$ from our base-

variation in corporate tax rates cannot account for the variation in capital accumulation across countries.

${ }^{2}$ The bias is upward (downward) if the true value of $\sigma$ is greater (smaller) than one.

${ }^{3}$ This logic works symmetrically and introduces downward bias if $\sigma$ is below one.

${ }^{4}$ There will be some degree of omitted variable bias unless the data happen to contain the entirety of every country's transition path. 
line sample of countries are below one and shrink when we omit the transitional term. In samples for which $\hat{\sigma}>1$, omitting the transitional term leads to larger point estimates, and the opposite holds for samples in which $\hat{\sigma}<1$. This is true across specifications, estimators, and samples. In short, cross-country data exhibit a weak correlation between labor's share and rental rates (once consistently proxied), which implies that $\sigma$ is near one.

Our proxy overcomes the omitted variable bias discussed above, but may introduce additional measurement error since it requires new data on consumption, and requires us to specify a utility function. We address this concern in two ways. First, we use investment prices as an instrument for our rental rate proxy. As long as the additional measurement error in our proxy is independent from the measurement error in investment prices, this cleanses our estimates of any extra attenuation bias relative to using investment prices alone. Second, we estimate the elasticity of substitution from subsamples with higher-quality time series data, such as developed or Organisation for Economic Co-operation and Development (OECD) countries and those with longer time series. We expect such countries to have less measurement error in investment prices in the first place, as well as better consumption data. Reassuringly, we estimate elasticities for these countries that do not differ significantly from our pooled estimates. ${ }^{5}$

The cross-country approach we employ is one of three empirical strategies used to identify the aggregate elasticity of substitution. One alternative, pursued by Antràs (2004), uses aggregate time series variation in the United States and estimates $\sigma \leq 1$, but requires imputation of effective capital to labor ratios in the presence of factoraugmenting technological growth. There is also a large literature on estimating the elasticity of substitution from micro data. A particularly relevant example is Oberfield and Raval (2014), who estimate these micro elasticities and aggregate them to compute a $\sigma$ substantially below one in the United States. ${ }^{6}$ This approach is the most precise, but also requires high-quality micro data that are unavailable in many countries. The benefit of the cross-country approach is that it requires only aggregate data on quantity flows and relative prices, but has thus far yielded substantially higher estimates of $\sigma$ than the other two strategies. Our estimates effectively reconcile the cross-country approach with the other two, while retaining its broad applicability.

\footnotetext{
${ }^{5}$ We also emphasize that most of our point estimates are slightly below one. If we could fully eliminate all measurement error, then we would expect most estimates to fall further below one and therefore strengthen our substantive conclusion.

${ }^{6}$ Chirinko (2008) and León-Ledesma, McAdam and Willman (2010) provide surveys of the literature on estimating the elasticity of substitution. The majority of estimates are below one.
} 
Although our estimates of $\sigma$ indicate that capital deepening has not caused the global decline in labor's share, the fact that it has fallen so broadly warrants an explanation. ${ }^{7}$ Our estimates lend support for explanations that do not require strong capital-labor substitutability to generate a decline in labor's share. Some examples include Autor et al. (2017) and Kehrig and Vincent (2017), who document that labor's share has fallen along with a rise in product-market concentration; Elsby, Hobijn and Şahin (2013), who estimate a strong correlation between industry-level trends in labor share and import competition; Grossman et al. (2017), who build an endogenous growth model with human capital in which labor's share falls due to slower productivity growth; and Glover and Short (2015), who estimate that an aging workforce reduces labor's share at the industry level.

We proceed by outlining the structural theory that relates labor's share to investment prices and show the economic importance of $\sigma \approx 1$ in that framework. We derive the appropriate reduced form model to estimate $\sigma$, then present our estimates, perform robustness tests, discuss previous estimates, and conclude.

\section{Labor's Share in Theory}

Our framework to estimate $\sigma$ is based on transition paths in the neo-classical growth model. The relative price of investment goods in country $i$ follows an exogenous and deterministic path to a new steady state, $P^{i}$. Starting at an initial $P_{0}^{i}$, which may or may not be a steady state, the path is written as:

$$
\log P_{t}^{i}=\log P^{i}+\log \xi_{t}^{i}
$$

where $P^{i}$ is the eventual steady state investment price and $\log \xi_{t}^{i}$ is a sequence that tends to zero (i.e., $\log \xi_{t}^{i}$ describes the transition path of investment prices). We think of the data as representing, for each country, a snapshot of such a transition path.

We assume that goods and factor markets are competitive. ${ }^{8}$ Each country is popu-

\footnotetext{
${ }^{7}$ While some of the decline may be due to mis-measurement or statistical imputation (see Rognlie (2015) for a discussion of housing's effect on capital's share; Bridgman (2014) on the importance of measuring depreciation and production taxes; Elsby, Hobijn and Şahin (2013) for a discussion of allocating proprietor's income between factors; and Koh, Santaeulàlia-Llopis and Zheng (2016) on how changing treatment of income from intellectual property affected labor's share in the U.S.), we expect these measurement issues to be alleviated by studying labor's share of the corporate sector wherever possible and using a broad cross section of countries at different points in development.

${ }^{8}$ Allowing for goods market markups is straightforward in theory, but introduces capital's share
} 
lated by a large number of representative households, each of which chooses sequences of consumption $c_{t}$, labor $n_{t}$, bonds $b_{t}$, and investment $x_{t}$ to solve the problem:

$$
\begin{array}{r}
\max _{\left(c_{t}, n_{t}, x_{t}, k_{t+1}, b_{t+1}\right)_{t=0}^{\infty}} \sum_{t=0}^{\infty} \beta^{t} u\left(c_{t}, 1-n_{t}\right) \\
\text { subject to: } \\
c_{t}+P_{t}^{i} x_{t}+Q_{t}^{i} b_{t+1}=R_{t}^{i} k_{t}+W_{t}^{i} n_{t}+b_{t} \\
k_{t+1}=(1-\delta) k_{t}+x_{t} \\
k_{0}, b_{0} \text { given. }
\end{array}
$$

We denote the price of a risk-free bond as $Q_{t}^{i}$, the real wage by $W_{t}^{i}$, and the rental rate for capital by $R_{t}$. We are intentionally agnostic about the determination of $Q_{t}^{i}$ and $P_{t}^{i}$. For $Q_{t}^{i}$, our estimation approach remains valid whether the bond market is closed and $Q_{t}^{i}$ is determined in equilibrium or each country is a small open economy and takes $Q_{t}^{i}$ exogenously. Likewise, it does not matter if the price of investment goods changes because each country experiences idiosyncratic shocks to the production technology for investment goods or if they face exogenous changes in the price of investment goods on the international market.

We will make use of the inter-temporal Euler equations

$$
\begin{aligned}
\frac{1}{Q_{t}^{i}} & =\frac{R_{t+1}^{i}+(1-\delta) P_{t+1}^{i}}{P_{t}^{i}}, \\
\frac{1}{Q_{t}^{i}} & =\frac{u_{c}\left(c_{t}^{i}, 1-n_{t}^{i}\right)}{\beta u_{c}\left(c_{t+1}^{i}, 1-n_{t+1}^{i}\right)} .
\end{aligned}
$$

The first is a no-arbitrage condition between the gross rates of return on bonds and investment and the second relates growth in marginal utility to the return on bonds. Combining these two equations yields a relationship between the rental rate, investment prices, and growth in the marginal utility of consumption:

$$
R_{t+1}^{i}=P_{t+1}^{i}\left[\frac{u_{c}\left(c_{t}^{i}, 1-n_{t}^{i}\right)}{\beta u_{c}\left(c_{t+1}^{i}, 1-n_{t+1}^{i}\right)} \frac{P_{t}^{i}}{P_{t+1}^{i}}+\delta-1\right] .
$$

A representative firm rents capital and hires labor to produce consumption goods and profit's share of income as distinct variables. These cannot be separated in the data, so require imputation. In Appendix 1, we estimate $\sigma$ using an imputation procedure suggested by KN. The estimates are similar to our baseline under perfect competition, but are subject to (potentially large) measurement error. 
using a constant returns to scale production function, which we assume has a constant elasticity of substitution

$$
Y_{t}^{i}=\left[\alpha_{k}^{i}\left(A_{t}^{i} K_{t}^{i}\right)^{\frac{\sigma-1}{\sigma}}+\left(1-\alpha_{k}^{i}\right)\left(B_{t}^{i} N_{t}^{i}\right)^{\frac{\sigma-1}{\sigma}}\right]^{\frac{\sigma}{\sigma-1}}
$$

where $\sigma$ is the elasticity of substitution between capital and labor and is the parameter of interest in this paper, as it determines the effect of investment prices on factor shares. The firm's capital demand equation is the basis for our empirical model and is given by:

$$
R_{t}^{i}=\alpha_{k}^{i}\left(A_{t}^{i}\right)^{\frac{\sigma}{\sigma-1}}\left(\frac{Y_{t}^{i}}{K_{t}^{i}}\right)^{\frac{1}{\sigma}}
$$

Denoting labor's share of income as $s_{t}^{i} \equiv 1-\frac{R_{t} K_{t}}{Y_{t}}$, the theoretical relationship between rental rates and labor's share can now be written as:

$$
1-s_{t}^{i}=\left(\alpha_{k}^{i}\right)^{\sigma}\left(\frac{A_{t}^{i}}{R_{t}^{i}}\right)^{\sigma-1} .
$$

All else being equal, a rise in the rental rate of capital will cause labor's share to rise (fall) when $\sigma$ is greater (smaller) than one. If we had data on the rental rate, $R_{t}^{i}$, then we could use Equation 11 to estimate $\sigma$. These data are not readily available, however, so we use Equation 8 to proxy for the rental rate. Combining Equations 8 and 11, we relate labor's share to investment prices and consumption:

$$
\Delta \log \left(1-s_{t}^{i}\right)=(\sigma-1)\left[\Delta \log A_{t}^{i}-\Delta \log P_{t}^{i}-\Delta \log \zeta_{t}^{i}\right]
$$

where $\zeta_{t}^{i}$ is the transitional term:

$$
\zeta_{t}^{i}=\frac{u_{c}\left(C_{t-1}^{i}, 1-N_{t-1}^{i}\right)}{\beta u_{c}\left(C_{t}^{i}, 1-N_{t}^{i}\right)} \frac{P_{t-1}^{i}}{P_{t}^{i}}+\delta-1
$$

Finally, we express the left-hand side in terms of labor's share rather than capital's share: ${ }^{9}$

$$
\Delta \log \left(1-s_{t}^{i}\right) \approx-\frac{\overline{s^{i}}}{1-\overline{s^{i}}} \Delta \log s_{t}^{i}
$$

where $\bar{x}^{i}$ is the average of variable $x$ for country $i$ over the years for which it is observed.

\footnotetext{
${ }^{9}$ This approximation is expositional, so that we reference correlations with labor's share rather than capital's share. We estimate similar $\hat{\sigma}$ without the approximation.
} 
This gives Equation 15, which will be the theoretical basis for our baseline estimating equation in Section 5.

$$
\frac{\overline{s^{i}}}{1-\overline{s^{i}}} \Delta \log s_{t}^{i}=(1-\sigma)\left[\Delta \log A_{t}^{i}-\Delta \log P_{t}^{i}-\Delta \log \zeta_{t}^{i}\right]
$$

\subsection{Bias From Omitting the Transitional Term}

We now explain how omitting the transitional term biases estimates away from one in the growth model. This is because both the transitional term and labor's share change more gradually than investment prices. The transitional term falls as investment prices decline, but does so slowly because households smooth consumption. Labor's share changes more slowly than investment prices because it requires the capital-labor ratio to rise, which takes time because capital is a stock variable. In Section 5, we show that this is relevant for our empirical estimate of $\sigma$.

We think of country $i$ 's path beginning from arbitrary values of $K_{0}$ and $P_{0}$ as the economy converges to a new steady state in response to a fall in the price of investment goods. We assume inelastic labor supply and close the model from Section 2 with an aggregate feasibility constraint and time series for investment prices, which requires that we add the following equations: ${ }^{10}$

$$
\begin{array}{r}
C_{t}^{i}+P_{t}^{i} X_{t}^{i}=Y_{t}^{i}, \\
\log P_{t}^{i}=\log P_{t-1}^{i}+\log \xi_{t}^{i}, \\
\log \xi_{t}^{i}=\rho \log \xi_{t-1}^{i}+(1-\rho) \Delta_{\xi} .
\end{array}
$$

Equation 18 specifies the transition path of investment prices, which slowly change by $100 \Delta_{\xi}$ percent.

We assume preferences are separable between consumption and leisure and that the intertemporal elasticity of consumption is one. All other parameter values are listed in Table 1. The most important is $\sigma$, which we assume to be slightly above one at $\sigma=1.01$. We then check whether estimates $\hat{\sigma}$ from two specifications of Equation 15 (with $\zeta$ included and omitted) can accurately recover $\sigma$. We do this by varying our first data point, $t_{0} \in\{3, \ldots 10\}$, and then estimating $\sigma$ using 20 years of the transition path. ${ }^{11}$

\footnotetext{
${ }^{10}$ This is equivalent to a two-sector model with a linear technology that transforms consumption goods into investment goods.

${ }^{11}$ We consider $\sigma=1.01$ because previous cross-country estimates have omitted $\beta_{\zeta}^{i}$ and found elasticities greater than one. The bias would be downward if we set $\sigma<1$.
} 
We begin by plotting time series of the log investment price, log capital's share, and $\log \zeta$ in order to provide intuition for how investment prices and $\zeta$ are predicted to covary along the transition path. These series are found in Figure 1. The investment price falls substantially early on and is then quite flat, while capital's share rises more gradually. Clearly, if an econometrician correlates trends in capital's share and investment prices and their time series begin after the first few years, then they compare an extremely slow decline in investment prices (nearly flat) to a positive trend in capital's share. They would therefore infer a large value of $\sigma$ rather than the value of 1.01 used to generate the series. If they include the trend in $\zeta$, however, then they will realize why capital's share continues to rise after investment prices flatten out - it is mirrored by a gradual fall in $\zeta$.

We quantify this intuition by calculating the elasticities directly under the fully specified model (assuming we know the utility function and parameter values) and then under the misspecified model with $\zeta$ omitted. We calculate $\sigma$ using the same procedure from the model: we first estimate the growth rates of each variable from $\log x_{t}=\beta_{0}+$ $\beta_{x} t+\eta_{x t}$ and then use these growth rates, $\beta_{x}$, to calculate $\sigma$. We define the elasticities calculated from the exact and omitted models as:

$$
\begin{array}{r}
\hat{\sigma}_{e}=1-\beta_{1-s} /\left[\beta_{P}+\beta_{\zeta}\right], \\
\hat{\sigma}_{o}=1-\frac{\beta_{1-s}}{\beta_{P}} .
\end{array}
$$

The bias is plotted in Figure 2, measured as $100\left(\frac{\hat{\sigma}_{i}-\sigma}{\sigma}\right)$. As expected, $\hat{\sigma}_{e}$ is near $\sigma=1.01$ no matter when the data begin (the flat line in Figure 2), while the misspecified estimate exhibits substantial upward bias.

\section{Economic Importance of $\sigma \approx 1$}

Our estimates of $\sigma$ are often statistically indistinguishable from one and our baseline estimates are below one on average, but it is useful to quantify the economic importance of $\sigma$ slightly above one, which is consistent with the upper bound of our confidence intervals. Figure 3 plots the series for global labor's share and investment prices against predicted labor's share for $\sigma=0.973$ and $\sigma=1.027$. These predicted series correspond to the average of our baseline point estimates and the average of the upper bound of the $95 \%$ confidence intervals for those estimates. Table 2 contains the cumulative change in 
predicted global labor's share for each of these elasticities. In each case, the predicted change in labor's share is small due to the elasticities being near one.

Whether a large share of the global decline in labor's share can be explained by capital deepening due to declining investment prices therefore rests on whether $\sigma$ is substantially greater than one. We now estimate $\sigma$ using various series, samples, and empirical models. The overwhelming majority of estimates indicate that $\sigma$ is near one and, if anything, smaller.

\section{Data}

Our data set is an unbalanced panel containing 104 countries with data available for some years between 1975 and 2010, which was used by KN. The panel includes data on labor's share, investment prices, and aggregate consumption. We will focus on mediumto long-run trends, rather than estimate $\sigma$ from year-to-year variation. ${ }^{12}$ We first obtain measures, for each country, of the medium- to long-run trends in the time series of each variable (we refer to this as the "first step"). We then estimate $\sigma$ in Equation 15 from the cross section of trends constructed in the first step (we refer to this as the "second step").

\subsection{Description of Variables}

We first describe the series for the first step and then describe the measure of the longrun trends used in the second step. For the first step, we need time series for the relative price of investment goods, labor's share, and consumption for each country.

For the relative price of investment goods, we present results from two publicly available series: the Penn World Table (PWT) and the World Bank's World Development Indicators (WDI). For labor's share of income we consider a hybrid measure that uses corporate-sector labor's share whenever available and an economy-wide measure of labor's share when corporate data are missing. ${ }^{13}$ The measure of labor's share uses corporate labor's share when available because it is cleaner: it avoids the difficulty of

\footnotetext{
${ }^{12}$ Our data construction and focus on medium- to long-run trends are shared by KN and the IMF. For all samples and specifications, point estimates using year-to-year changes are consistently near one and never statistically different.

${ }^{13}$ The labor's share series include time series constructed from country-specific sources, as well as series from OECD and UN data sets. We will present estimates using each labor's share series, as well as the unadjusted OECD/UN measures.
} 
allocating proprietor's income between labor and capital. The hybrid series is our baseline in order to maximize sample size in the second step, although we get similar results using only corporate labor's share, as seen in Table 9.

To construct the transitional term, we use real per-capita consumption from the PWT. We then assume a utility function that is separable between consumption and leisure, with a constant inter-temporal elasticity of substitution: $u\left(c_{t}, 1-N_{t}\right)=\frac{c_{t}^{1-\theta}}{1-\theta}+$ $\nu\left(1-N_{t}\right)$. Our baseline further restricts these preferences to be consistent with balanced growth, so that $\theta=1$ and $u_{c}\left(c_{t}, 1-N_{t}\right)=c_{t}^{-1}$. Finally, we set $\delta=0.10$ and $\beta=0.91$, although we have verified that our estimates are robust to these values. ${ }^{14}$

For country-year observations where consumption growth is sufficiently small, $\zeta_{t}^{i}$ measured by Equation 13 may be negative and $\log \zeta_{t}^{i}$ undefined. Country-year observations for which $\log \zeta_{t}^{i}$ is undefined are dropped (this typically amounts to fewer than $2 \%$ of country-year observations, as reported in Table 3). Since we must drop a small share of country-years for which $\zeta_{t}^{i}$ is undefined, we also report estimates using the ex-post real interest rate as a proxy for $\frac{U_{c}\left(c_{t}, \ell_{t}\right)}{\beta U_{c}\left(c_{t+1}, \ell_{t+1}\right)}$. Data on the real interest rate come from the World Bank's WDI, and is measured as the deposit rate less the growth rate of the gross domestic product (GDP) deflator. ${ }^{15}$ The real interest rate has the advantage of being independent of preference parameters, $\theta$ and $\beta$, but interest rates are not available for all countries in our sample.

In the first step of estimation, we extract the long-run trend for each time series $x_{t}^{i}$ described above, for each country $i$, by estimating $\beta_{x}^{i}$ via ordinary least squares (OLS):

$$
\log x_{t}^{i}=a_{x}^{i}+\beta_{x}^{i} t+\eta_{x, t}^{i}
$$

We then have a triplet of these coefficients, $\left(\beta_{s}^{i}, \beta_{P}^{i}, \beta_{\zeta}^{i}\right)$, for each country, which represent annual growth trends in each variable. ${ }^{16}$

In Table 4, we present summary statistics for trends in investment prices, the transitional term $\zeta$, the resulting rental rate proxy, and the predicted rental rates from the first stage of our instrumental variable (IV) regression. On average, the trends in each price series and transitional term are negative, but there is substantial heterogeneity. We emphasize two patterns. First, the rental rate is substantially more volatile than in-

\footnotetext{
${ }^{14}$ We have also estimated the model with different values of $\theta$ and obtained similar results. Especially interesting is the case when $\theta=0$, so that $\beta_{\zeta}^{i}=0$ for all countries, and investment price trends alone proxy for rental rates. Even this specification yields an estimate of $\sigma$ near one for many samples (see Table 13, columns " $T_{\min }=10 "$ and " $T_{\min }=20 "$ ).

${ }^{15}$ Estimates are robust to using lending rates and consumer price index (CPI) growth.

${ }^{16}$ We refer to these estimates as $\beta_{x}^{i}$ rather than $\hat{\beta}_{x}^{i}$ to save notation.
} 
vestment prices alone, even after we cleanse it of extra measurement error by projecting it onto investment prices. Second, the correlation of prices (and therefore our cleansed rental rate proxy) is near zero for both series, though slightly negative for this sample. Taken together, these two moments explain why we find an elasticity of substitution (slightly) below one and why omitted variable bias generates estimates further from one when investment prices alone proxy for rental rates.

\subsection{Sample Selection}

Sample selection poses a tradeoff between time series length in the first step and crosssectional sample size in the second step. The threshold for a country's inclusion in the second step is the length of its investment price and labor's share time series, $T_{\min }$. On the one hand, we want enough years of data to calculate long-run trends. On the other hand, we want as many countries in the second step as possible, so we do not want to set $T_{\min }$ too high. ${ }^{17}$ Our preferred threshold drops countries with fewer than 10 years of labor share and investment price data, which leaves us with $77-86$ countries for estimating Equation 15, depending on which labor's share and investment price series we use.

\section{Estimation Results}

In order to derive an empirical regression model, we assume that $A_{t}^{i}$ consists of a worldwide trend, $\gamma$, and a country-specific trend, $\varepsilon^{i}$ :

$$
\log A_{t}^{i}=\frac{1}{1-\sigma}\left(\gamma t+\varepsilon^{i} t\right)
$$

The reduced-form regression equation corresponding to Equation 15 is given by:

$$
\frac{\overline{s^{i}}}{1-\overline{s^{i}}} \beta_{s}^{i}=\gamma+(\sigma-1)\left(\beta_{P}^{i}+\beta_{\zeta}^{i}\right)+\varepsilon^{i} .
$$

We assume that country-specific trends in capital-augmenting productivity $\left(\varepsilon^{i}\right)$ are uncorrelated with average investment price growth and estimate Equation 23 by instrumenting the sum $\beta_{P}^{i}+\beta_{\zeta}^{i}$ with $\beta_{P}^{i}$. This approach ensures that we identify $\sigma$ from

\footnotetext{
${ }^{17}$ Setting $T_{\min }$ low also introduces more emerging-markets countries for which data may be poor and therefore attenuate estimates of $\sigma$. We address this concern by estimating $\sigma$ separately for developed and emerging-market economies and by considering a broad range of $T_{\min }$ for robustness.
} 
cross-sectional variation in rental rates induced by variation in investment price trends, while also correcting for measurement error introduced by $\beta_{\zeta}^{i}$. Our baseline regressions have strong instruments, with a minimal first-stage F statistic of 41.1 .

Table 5 reports our estimates for each combination of labor's share and investment price series. The point estimates of $\sigma$ are typically below one and the average across data sets is $\hat{\sigma}=0.973$. All point estimates are near and statistically indistinguishable from one; capital deepening due to declining investment prices cannot account for the global decline in labor's share.

\subsection{Bias From Omitting $\beta_{\zeta}^{i}$}

We have discussed the importance of transitional dynamics (i.e., $\beta_{\zeta}^{i}$ ) for consistently estimating $\sigma$ in Section 2.1, which can be understood empirically as a form of omitted variable bias. The relationship between the point estimate when $\beta_{\zeta}^{i}$ is omitted, $\hat{\sigma}^{O M}$, and the true elasticity, $\sigma$, is given by ${ }^{18}$

$$
\hat{\sigma}^{O M}-1=(\sigma-1) \frac{V\left(\beta_{P}^{i}\right)+C V\left(\beta_{P}^{i}, \beta_{\zeta}^{i}\right)}{V\left(\beta_{P}^{i}\right)} .
$$

This equation shows that the overall effect of a declining rental rate on labor's share, $\sigma-1$, is biased away from the true effect by a scaling factor greater than one as long as investment prices and the transitional term are positively correlated. In our baseline sample using the PWT investment price series, the cross-sectional variance of $\beta_{P}^{i}$ is $5.7 \%$ and the covariance between $\beta_{P}^{i}$ and $\beta_{\zeta}^{i}$ is $4.6 \%$, which generates a scaling factor of 1.8 (i.e., $\hat{\sigma}^{O M}-1$ is biased away from $\sigma-1$ by $81 \%$ ).

Table 6 shows that omitting $\beta_{\zeta}^{i}$ generates smaller $\hat{\sigma}$ for each data set, except for the KN-WDI data when $\hat{\sigma}=\hat{\sigma}^{O M}=1.000$. For each series, $\beta_{\zeta}^{i}$ and $\beta_{P}^{i}$ are positively correlated. Therefore, if $\sigma$ is slightly below one in reality, as suggested by our IV estimates, then omitting $\beta_{\zeta}^{i}$ introduces downward bias in $\hat{\sigma}$. On the other hand, if $\sigma>1$, as estimated in previous studies, then omitting $\beta_{\zeta}^{i}$ introduces upward bias.

\subsection{Measurement Error}

We are concerned with measurement error, which would bias our estimates of $\sigma$ towards one. The main issue is that our rental rate proxy includes the transitional term $\zeta$, which

\footnotetext{
${ }^{18}$ The formula in Equation 24 is exact for the OLS estimator, but qualitatively useful for our IV estimates, which we prefer because of measurement error in $\beta_{\zeta}^{i}$.
} 
is measured with error above and beyond investment prices themselves. This motivated our use of investment price trends as instruments for our rental rate proxy in order to cleanse our proxy from any additional measurement error introduced by $\zeta$. To see this point, let $\psi_{P}^{i}$ be the measurement error in $\beta_{P}^{i}$ and $\psi_{\zeta}^{i}$ be the measurement error in $\beta_{\zeta}^{i}$. Then the IV estimate, $\hat{\sigma}^{I V}$, is given by

$$
\hat{\sigma}^{I V}-1=(\sigma-1) \frac{\operatorname{cov}\left(\beta_{P}^{i}+\beta_{\zeta}^{i}, \beta_{P}^{i}\right)}{\operatorname{cov}\left(\beta_{P}^{i}+\beta_{\zeta}^{i}, \beta_{P}^{i}\right)+\operatorname{var}\left(\psi_{P}^{i}\right)+\operatorname{cov}\left(\psi_{P}^{i}, \psi_{\zeta}^{i}\right)} .
$$

We have no reason to expect the measurement errors in $\beta_{P}^{i}$ and $\beta_{\zeta}^{i}$ to be correlated, so the IV estimator is attenuated towards zero only through variation in investment prices. That is, including $\zeta$ in our proxy for rental rates and instrumenting with investment price trends introduces no additional attenuation relative to investment prices alone, while overcoming the omitted variable bias from excluding it.

While we cannot quantify how much measurement error is left in investment price trends, we now show that our point estimates are similar across subsamples with lowerand higher-quality data. From this we conclude that measurement error in investment price trends is either small, or that it is constant across countries that differ dramatically from one another. We first estimate $\sigma$ for developed/OECD countries separately from emerging markets/non-OECD countries. Table 7 presents estimates of $\sigma$ for developed and developing countries separately. Developed countries have a slightly higher point estimate on average, but neither elasticity is significantly different from one. Table 8 shows the same pattern for OECD and non-OECD countries. We therefore find no evidence that $\sigma$ varies significantly by development status or data quality.

This slice of the data is interesting beyond our check for measurement error, because the elasticity of substitution may depend directly on a country's development level. For example, the elasticity may change as a country becomes more developed and adopts new technologies. Whether the elasticity rises or falls with development is an open question and there is conflicting evidence regarding the effect of development on $\sigma$. Oberfield and Raval (2014) estimate a higher elasticity for India than for the United States, while the IMF estimates a higher elasticity for developed than for emergingmarkets countries. ${ }^{19}$ Our estimates indicate that developed countries have an elasticity indistinguishable from one and that developing countries may have a somewhat lower

\footnotetext{
${ }^{19}$ Oberfield and Raval estimate establishment-level elasticities and then aggregate using input-output tables, so differ substantially from us methodologically. The IMF uses an approach closer to ours, but omits $\beta_{\zeta}^{i}$, which we discuss in Section 6.2.
} 
elasticity, though the differences are small and statistically insignificant.

In summary, we have used an IV estimator to alleviate concerns of additional mea-

surement error from $\beta_{\zeta}^{i}$. Investment price trends may still cause attenuation, but whatever is there must not vary substantially across countries with differing data quality. We therefore think our point estimates of an elasticity slightly below one are compelling, although emphasize that further eliminating measurement error would push most of our estimates further below one. This strengthens our conclusion that declining investment prices have not driven the global decline in labor's share.

\subsection{Capital-Augmenting Technology and Investment Prices}

A remaining source of bias in $\hat{\sigma}$ is the possibility of correlation between capital-augmenting technological growth and investment prices (i.e., $\varepsilon^{i}$ and $\beta_{P}^{i}$ ). If capital-augmenting technology growth is negatively correlated with investment price trends, then our point estimates will be biased away from one. Since we have estimated $\sigma \approx 1$, the resulting bias would be small and only further dampen the effect of investment prices on labor's share in either direction. However, if $\nu^{i}$ and $\beta_{P}^{i}$ are positively correlated, then our point estimates are biased towards one. Since most of our estimates put $\sigma$ slightly below one, correcting for this bias (if it is there) would further align the cross-country with previous identification strategies that typically estimate $\sigma<1$, without changing our substantive conclusion that investment price trends cannot account for the global trend in labor's share of income.

\subsection{Further Robustness}

We now explore the robustness of our estimates to alternative measures of labor's share, definitions of $\zeta^{i}$, subsamples of countries, and regression methods. The overwhelming majority of estimates indicate an elasticity near or below one.

We first estimate $\sigma$ using corporate labor's share rather than the economy-wide labor's share measure from our baseline, the results of which are reported in Table 9. This alleviates concerns about changes in proprietor's income, which has been shown to have large effects on the trend in labor's share in the U.S. (Elsby, Hobijn and Şahin (2013)). On the other hand, this reduces our sample size because some countries (mostly emerging markets) do not have data for corporate labor's share. Our point estimates rise slightly on average, to $\hat{\sigma}=1.009$, but the implied effect of investment prices on labor's share is still economically and statistically insignificant. 
We next consider an alternative measure of $\zeta_{t}^{i}$, since this term required us to assign a utility function and extra parameter values. We instead proxy for the ratio of marginal utilities using a measure of the real risk-free interest rate by setting

$$
\zeta_{t}^{i}=\frac{P_{t-1}^{i}}{P_{t}^{i}}\left(1+r_{t}^{i}\right)+\delta-1
$$

where $1+r_{t}^{i} \equiv \frac{1}{Q_{t-1}^{i}}$. This definition is agnostic about the utility function of the household, as well as the discount factor, but still requires a value of $\delta$, which we set at 0.10 as in the baseline. As reported in Table 10, our point estimates fall under this specification, especially when using the WDI investment price series, and the average is $\hat{\sigma}=0.948$. Estimates of $\sigma$ using real interest rates imply that the global decline in investment prices should have increased labor's share even more than implied by our baseline estimates.

We next estimate $\sigma$ from alternative cross-sectional samples by varying our exclusion restriction $T_{\min } \in\{5,6, \ldots 20\}$. It is useful to consider the effect of $T_{\min }$ for both economic and statistical reasons. Economically, there may be substantial cross-country heterogeneity in capital-labor substitutability, which would require us to make any statement about the effect of investment prices on labor's share contingent. Statistically, we further explore the tradeoff between sample size and data quality, since lower values of $T_{\min }$ increase our cross-sectional sample size, but higher values give longer time series to calculate $\beta_{L S}^{i}, \beta_{\zeta}^{i}$, and $\beta_{P}^{i}$. Figure 4 plots each point estimate and $90 \%$ confidence interval across all of our data sets. Estimates of $\sigma$ using the PWT's price series vary only slightly as we change samples, consistent with a near-constant elasticity of substitution across countries, while the WDI-based estimates rise and then fall across samples. Overall, only $6.25 \%$ ( 4 of 64 ) of point estimates are significantly above one in the statistical sense and most (43 of 64) are below one in value.

Finally, we consider the effect of outliers on $\hat{\sigma}$ by using the robust regression estimator of Li (2011). Intuitively, this method fits OLS to the data, then weights each observation as a function of its distance from the OLS line and a user-supplied tuning parameter, and then estimates a weighted OLS regression. This procedure is iterated upon until convergence. Robust regression is useful if one believes that the regression errors are non-normal, but is otherwise less efficient than OLS; the tuning parameter allows the user to balance this tradeoff. Table 11 compares our baseline estimates of $\sigma$ to those from robust regression, using a bold tuning parameter and a conservative one. ${ }^{20}$ The

\footnotetext{
${ }^{20} \mathrm{~A}$ lower value of the tuning parameter down-weights outliers more severely and is more likely to drop observations at early iterations of the algorithm by setting their weight to zero. Our bold tuning
} 
average point estimate is essentially identical across procedures and all estimates are statistically insignificant from one.

In summary, cross-country trends in investment prices and labor's share suggest that the elasticity of substitution between capital and labor is less than or equal to one. The global decline in labor's share cannot be accounted for by capital deepening in response to falling investment goods prices.

\section{Comparison With Previous Estimates}

Previous cross-country estimates that identify $\sigma$ from investment price and labor share trends argue that declining investment prices can account for much of the decline in labor's share, either globally or for a subset of countries. We now reconsider these findings using our methodology. Accounting for transitional dynamics brings these previous estimates much closer to our own. On balance, there is little cross-country evidence for $\sigma$ substantially above one.

\subsection{Karabarbounis and Neiman, 2014}

KN use the same data set and theoretical framework as us, but estimate a much larger value of $\sigma \approx 1.26$ and conclude that investment prices can account for half of the global decline in labor's share since the early 1980s. Our estimation procedure differs from theirs in three ways. First, our proxy for rental rates includes the transitional term, $\beta_{\zeta}^{i}$. Second, they report estimates from a robust regression estimator, whereas our baseline uses linear instrumental variables. Finally, we estimate $\sigma$ from a larger cross-sectional data set than KN because we include all countries with time series longer than $T_{\min }=10$, whereas they require $T_{\min }=15$. We consider the importance of each of these choices.

We first present summary statistics for the KN sample. Table 12 shows that investment price trends are somewhat less variable for this smaller cross-sectional sample, but still understate the cross-sectional variation in rental rate trends, even after correcting for measurement error. Furthermore, the correlation between investment prices and labor's share is positive in this sample, but still very low. In fact, our preferred rental rate proxy is actually more positively correlated with labor's share than are investment prices alone.

value is the default value implemented by Stata, which is near the lower bound suggested by Goodall (1983), and the only estimator reported by KN. Our conservative value is the upper bound suggested by Goodall (1983). 
Using a theoretically consistent proxy for rental rates is our most economically important difference with $\mathrm{KN}$ and has large effects on $\hat{\sigma}$, which we isolate by estimating the model with $\beta_{\zeta}^{i}$ included, but using the same cross section of countries and the same robust regression estimator as KN. Specifically, we first estimate KN's exact specification, which we are able to match precisely in the column "KN" in Table 13, the average of which is $\hat{\sigma}=1.26$. We then save the weights produced by the robust regression algorithm and use them to estimate a weighted regression with our interest rate proxy on the right-hand side, the results of which are listed in column "Include $\beta_{\zeta}^{i}$ ". ${ }^{21}$ The average estimate falls from $\hat{\sigma}=1.26$ to 1.11 , which means that the effect of investment prices on labor's share is reduced by nearly $60 \%$. While the omitted variable bias calculation is invalid for the robust regression estimator, the reduction in $\sigma^{O M}-1$ is in line with the scaling factor we calculated in Section 5.1.

The choices of estimator and sample selection are also important. The "IV" column of Table 13 reports $\hat{\sigma}$ from samples with $T_{\min }=15$ but using the IV estimator from our baseline rather than the robust regression estimator. This reduces the average point estimate further to $\hat{\sigma}=1.07$ and, for the PWT data, reduces the elasticity to one. As we discussed in Section 5.4, the robust regression estimator with Stata's default tuning parameter severely down-weights outliers. In the case of the PWT investment price series, for example, it puts zero weight on three countries, effectively reducing the crosssectional sample size. KN's original rationale for relying exclusively on this specific robust regression estimator was that their cross-sectional sample size was small. We therefore find it useful to directly assess the effect of sample size by varying $T_{\min }$.

Our baseline results used a larger cross-sectional sample by setting $T_{\min }=10$, so within that larger sample we've already shown that $\sigma \approx 1$ if estimated with a transitionconsistent proxy for the rental rate and a standard linear regression framework. We therefore use the robust regression estimator and omit $\beta_{\zeta}^{i}$ when estimating $\sigma$ on this larger sample, which is shown in column $T_{\min }=10$ of Table 13 . The point estimates of $\sigma$ are near one, with some above and some below. Economically, these point estimates imply little to no effect of investment prices on labor's share. Statistically, they are indistinguishable from one with relatively tight standard errors (smaller than the $T_{\min }=15$ sample used by KN). Finally, since the added countries may have more measurement

\footnotetext{
${ }^{21}$ The robust regression estimator would re-weight countries in the specification with $\beta_{\zeta}^{i}$ included. We have kept the weighting matrix constant across these specifications in order to test these difference between $\hat{\sigma}^{O M}$ and $\hat{\sigma}$. We compute Z-statistics of $-1.71,-2.16,-1.43$, and -2.37 as we move down the rows in Table 13. Our rental rate proxy therefore reduces the economic effect of investment prices on labor's share, typically with strong statistical significance.
} 
error when setting $T_{\min }=10$ instead of 15 , we report the same robust regression estimates of the misspecified model with a smaller (but higher-quality) sample in column $T_{\min }=20$ and again find estimates close to one (although with larger standard errors due to the smaller sample).

In summary, KN estimated a large value $\sigma \approx 1.26$ and concluded that capital deepening due to falling investment prices could therefore account for half of the global decline in labor's share. This large estimate is at odds with other identification schemes, as well as the cross-country estimates of Backus, Henriksen and Storesletten (2008). This discrepancy is due to model specification, the weighted estimator, and an atypical sample. Changing any one of them brings the cross-country estimates of $\sigma$ closer to previous studies (and to our baseline estimates).

\subsection{IMF WEO, 2017}

The IMF's World Economic Outlook (2017) find conditional evidence that declining investment prices reduce labor's share. Using data from 1992 to 2014, the IMF estimates that labor's share falls in response to declining investment prices in developed countries, although the opposite is true for emerging markets and these two responses offset one another when developed and emerging market countries are pooled.

The role of investment prices in reducing labor's share is further limited when we account for the transitional term. In Table 14 we estimate the IMF's partial-elasticity model for each group of countries, but with $\beta_{\zeta}^{i}$ included in the proxy for rental rates. ${ }^{22}$ The column labeled "IMF" in Table 14 shows that the IMF estimates a larger difference between developed and emerging-market countries than we found in Section 5.2, while column "IV" of Table 14 shows that the estimates move closer to and are insignificant from zero if we account for the transitional term, $\beta_{\zeta}^{i}$, as in our baseline (using $\beta_{P}^{i}$ as an instrument). Most importantly, we estimate a much lower and insignificant partial elasticity for developed countries, indicating that even their decline in labor's share cannot be accounted for by capital accumulation due to falling investment prices.

\footnotetext{
${ }^{22}$ The IMF's regression model does not identify $\sigma$ because they use percentage-point changes in labor's share rather than percentage changes, which is why we call their estimates "partial elasticities."
} 


\section{Conclusion}

The aggregate elasticity of substitution between capital and labor is central to understanding the effect of capital accumulation on factor shares of income. The global decline in labor's share has drawn substantial attention to this parameter - if it is sufficiently above one, then the observed decline in investment prices provides a simple explanation for the decline in labor's share. We have shown how to consistently estimate this elasticity by using a theoretically derived proxy for rental rates, which depends on investment prices as well as consumption growth. Our estimates indicate that $\sigma$ is near one and, if anything, below. We conclude that the global decline in labor's share has occurred for reasons other than capital deepening in response to declining investment prices. 


\section{References}

Antràs, Pol. 2004. "Is the US Aggregate Production Function Cobb-Douglas? New Estimates of the Elasticity of Substitution." Contributions to Macroeconomics, 4(1): 134.

Autor, David, David Dorn, Lawrence F Katz, Christina Patterson, John Van Reenen, et al. 2017. "Concentrating on the Fall of the Labor Share." IZA Institute of Labor Economics Discussion Paper, 10539.

Backus, David, Espen Henriksen, and Kjetil Storesletten. 2008. "Taxes and the Global Allocation of Capital." Journal of Monetary Economics, 55(1): 48-61.

Bridgman, Benjamin. 2014. "Is Labor's Loss Capital's Gain? Gross Versus Net Labor Shares." Bureau of Economic Analysis BEA Working Paper 0114.

Chirinko, Robert S. 2008. "Sigma: The Long and Short of It." Journal of Macroeconomics, 30(2): $671-686$.

Elsby, Michael WL, Bart Hobijn, and Ayşegül Şahin. 2013. "The Decline of the US Labor Share." Brookings Papers on Economic Activity, 2013(2): 1-63.

Glover, Andrew, and Jacob Short. 2015. "Demographic Origins of the Decline in Labor's Share."

Goodall, Colin. 1983. M-Estimators of Location: An Outline of the Theory. Vol. 5, New York: Wiley.

Grossman, Gene M, Elhanan Helpman, Ezra Oberfield, and Thomas Sampson. 2017. "The Productivity Slowdown and the Declining Labor Share: A Neoclassical Exploration." National Bureau of Economic Research Working Paper 23853.

Kaldor, Nicholas. 1957. "A Model of Economic Growth." The Economic Journal, 67(268): 591-624.

Karabarbounis, Loukas, and Brent Neiman. 2014. "The Global Decline of the Labor Share." The Quarterly Journal of Economics, 129(1): 61-103.

Kehrig, Matthias, and Nicolas Vincent. 2017. "Growing Productivity Without Growing Wages: The Micro-Level Anatomy of the Aggregate Labor Share Decline." Economic Research Initiatives at Duke (ERID) Working Paper 244. 
Koh, Dongya, Raül Santaeulàlia-Llopis, and Yu Zheng. 2016. "Labor Share Decline and Intellectual Property Products Capital." Barcelona Graduate School of Economics Working Paper 927.

León-Ledesma, Miguel A., Peter McAdam, and Alpo Willman. 2010. "Identifying the Elasticity of Substitution with Biased Technical Change." American Economic Review, 100(4): 1330-57.

Li, Guoying. 2011. "Robust Regression." Exploring Data Tables, Trends, and Shapes, Chapter 8, 281-343. John Wiley and Sons, Ltd.

Oberfield, Ezra, and Devesh Raval. 2014. "Micro Data and Macro Technology." National Bureau of Economic Research Working Paper 20452.

Piketty, Thomas. 2014. Capital in the twenty-first century. Cambridge (MA): Harvard University Press.

Piketty, Thomas, and Gabriel Zucman. 2014. "Capital is Back: Wealth-Income Ratios in Rich Countries 1700-2010." The Quarterly Journal of Economics, 129(3): 12551310.

Rognlie, Matthew. 2015. "Deciphering the Fall and Rise in the Net Capital Share: Accumulation or Scarcity?" Brookings Papers on Economic Activity, 2015(1): 1-69.

World Economic Outlook, IMF. 2017. "World Economic Outlook: Understanding the Downward Trend in Labor Income Shares." IMF, Washington DC. 


\section{Tables}

\subsection{Parameter Values for Simulation}

Table 1: Parameter Values

\begin{tabular}{l|c|l}
\hline \hline Parameter & Value & Target \\
\hline$\sigma$ & 1.01 & Illustration \\
$\beta$ & 0.91 & KN $(2014)$ \\
$\delta$ & 0.10 & KN (2014) \\
$\alpha_{k}$ & 0.35 & Capital share 0.34 \\
$A$ & 0.81 & Normalize $Y=1$ \\
$\theta$ & 1.0 & Log utility \\
$\rho$ & 0.5 & Speed of price fall \\
$\Delta_{\infty}$ & $-10 \%$ & Eventual price fall \\
\hline \hline
\end{tabular}

Notes: Parameter values used to generate simulated series for investment prices, rental rates, and factor shares from growth model displayed in Figures 1 and 2. 


\subsection{Comparison of Predicted Global Labor's Share}

Table 2: Comparison of Predicted Global Labor's Share (1976-2010)

\begin{tabular}{c|ccc}
\hline \hline & \multicolumn{3}{|c}{$\sigma$ Estimate } \\
& Data & 0.973 & 1.027 \\
\hline$\Delta L S$ & & & \\
& -0.085 & +0.006 & -0.005 \\
Share of Data & & $-6.59 \%$ & $+6.41 \%$ \\
\hline \hline
\end{tabular}

Notes: Predictions of labor's share are generated at the country level using observed $\beta_{P}^{i}$ and $\beta_{\zeta}^{i}$, then aggregated by a GDP-weighted average across countries. Global labor's share and investment price are constructed as GDP-weighted averages across countries. GDP is measured in U.S. dollars at market exchange rates. The change in labor's share is measured as the difference in the levels of labor's share in 2010 and 1976. 


\subsection{Variable Construction and Summary Statistics}

Table 3: Country-Year Observations

\begin{tabular}{l|ccc}
\hline \hline Sample & Max Obs. & Used Obs. & Dropped Obs. \\
\hline Hybrid, PWT & 1575 & 1548 & $27(1.7 \%)$ \\
Hybrid, WDI & 1517 & 1484 & $33(2.2 \%)$ \\
Corporate, PWT & 961 & 952 & $9(0.9 \%)$ \\
Corporate, WDI & 952 & 941 & $11(1.2 \%)$ \\
\hline \hline \multicolumn{4}{|c}{ OECD and UN Data } \\
\hline Hybrid, PWT & 1350 & 1330 & $20(1.5 \%)$ \\
Hybrid, WDI & 1306 & 1281 & $25(1.9 \%)$ \\
Corporate, PWT & 918 & 909 & $9(1.0 \%)$ \\
Corporate, WDI & 906 & 895 & $11(1.2 \%)$ \\
\hline \hline
\end{tabular}

Notes: We estimate $\sigma$ using different panels for labor's share of income and investment prices, labeled in the rows above. Our proxy for rental rates requires us to compute the variable $\zeta_{t}^{i}$, which may be undefined for sufficiently low growth rates of aggregate consumption. Column "Dropped Obs." displays the number and share of country-year observations for which our variable $\zeta_{t}^{i}$ is undefined. We drop these country-year observations when calculating the trends for those countries. 
Table 4: Summary Statistics $\left(T_{\min }=10\right)$

\begin{tabular}{c|cccc}
\hline \hline & $\beta_{P}^{P W T}$ & $\beta_{\zeta}$ & $\beta_{P}^{P W T}+\beta_{\zeta}$ & $\beta_{P}^{P \widehat{W T}+\beta_{\zeta}}$ \\
\hline Mean & -0.46 & -0.35 & -0.82 & -0.82 \\
St. dev. & 2.39 & 3.13 & 4.97 & 4.32 \\
$\rho\left(\beta_{x}, \beta_{L S}\right)$ & -0.14 & -0.23 & -0.21 & -0.14 \\
$\rho\left(\beta_{x}, \beta_{P}^{P W T}\right)$ & 1.00 & 0.62 & 0.87 & 1.00 \\
\hline & $\beta_{P}^{W D I}$ & $\beta_{\zeta}$ & $\beta_{P}^{W D I}+\beta_{\zeta}$ & $\beta_{P}^{W D I}+\beta_{\zeta}$ \\
\hline Mean & -0.37 & -0.39 & -0.76 & -0.76 \\
St. dev. & 2.30 & 3.99 & 5.32 & 3.84 \\
$\rho\left(\beta_{x}, \beta_{L S}\right)$ & -0.001 & -0.07 & -0.05 & -0.001 \\
$\rho\left(\beta_{x}, \beta_{P}^{W D I}\right)$ & 1.00 & 0.39 & 0.72 & 1.00 \\
\hline \hline
\end{tabular}

Notes: Summary statistics for cross-sectional trends in prices and rental rate trends for PWT and WDI panels. Rows show mean, cross-sectional standard deviation, and correlations with labor share, and correlation with investment price trends alone. 


\subsection{Estimates of $\sigma$}

All regressions use the left-hand side of Equation 23 as the dependent variable. The independent variable is either the right-hand side of Equation 23 or, in the case of the misspecified models, the trend in investment prices alone.

Table 5: Baseline Estimates

\begin{tabular}{c|ccc}
\hline \hline Investment Prices & $\hat{\sigma}$ & $90 \%$ C.I. & Obs \\
\hline PWT & 0.955 & {$[0.899,1.010]$} & 86 \\
WDI & 1.000 & {$[0.942,1.058]$} & 85 \\
\hline \multicolumn{4}{c}{ OECD and UN Data } \\
\hline PWT & 0.942 & {$[0.884,1.001]$} & 79 \\
WDI & 0.993 & {$[0.947,1.038]$} & 77 \\
\hline Average & 0.973 & \\
\hline \hline
\end{tabular}

Notes: Column $\hat{\sigma}$ displays estimate from

$$
\frac{\bar{s}^{i}}{1-\bar{s}^{i}} \beta_{s}^{i}=\gamma+(\sigma-1)\left(\beta_{P}^{i}+\beta_{\zeta}^{i}\right)+\epsilon^{i}
$$

with $\beta_{P}^{i}+\beta_{\zeta}^{i}$ instrumented using $\beta_{P}^{i}$. Rows correspond to data set used to compute investment price trends. Top two rows use baseline hybrid measure of the labor share and bottom two use OECD/UN labor share series. 
Table 6: Baseline vs. Omitted Variable Specification

\begin{tabular}{c|cc|ccc|c}
\hline \hline & \multicolumn{3}{|c}{ Baseline } & \multicolumn{4}{c}{ Omitted $\beta_{\zeta}^{i}$} \\
\hline & $\hat{\sigma}$ & $90 \%$ C.I. & $\hat{\sigma}$ & $90 \%$ C.I. & Obs. \\
\hline PWT & 0.955 & {$[0.899,1.010]$} & 0.918 & {$[0.951,1.034]$} & 86 \\
WDI & 1.000 & {$[0.942,1.058]$} & 1.000 & {$[0.967,1.040]$} & 85 \\
\hline \hline \multicolumn{6}{c}{ OECD and UN Data } \\
\hline PWT & 0.942 & {$[0.884,1.001]$} & 0.894 & {$[0.959,1.026]$} & 79 \\
WDI & 0.993 & {$[0.947,1.038]$} & 0.985 & {$[0.971,1.020]$} & 77 \\
\hline Average & 0.973 & 0.949 & \\
\hline \hline
\end{tabular}

Notes: Column $\hat{\sigma}$ displays estimate of $\sigma$ from

$$
\frac{\bar{s}^{i}}{1-\bar{s}^{i}} \beta_{s}^{i}=\gamma+(\sigma-1)\left(\beta_{P}^{i}+\beta_{\zeta}^{i}\right)+\epsilon^{i}
$$

with $\beta_{P}^{i}+\beta_{\zeta}^{i}$ instrumented with $\beta_{P}^{i}$, while column "Omitted $\beta_{\zeta}^{i}$ " displays estimate of $\sigma^{O M}$ from

$$
\frac{\bar{s}^{i}}{1-\bar{s}^{i}} \beta_{s}^{i}=\gamma+\left(\sigma^{O M}-1\right) \beta_{P}^{i}+\epsilon^{i}
$$

Rows correspond to data set used to compute investment price trends. Top two rows use baseline hybrid measure of the labor share and bottom two use OECD/UN labor share series. All estimates include all countries for which investment prices and labor's share of income are available for at least $T_{\min }=10$ years. 
Table 7: Comparison of Developed vs. Emerging-Market Economies

\begin{tabular}{lcccccc}
\hline \hline & \multicolumn{3}{c}{ Developed } & \multicolumn{5}{c}{ Emerging } \\
\hline & $\hat{\sigma}$ & $90 \%$ C.I. & Obs. & $\hat{\sigma}$ & $90 \%$ C.I. & Obs. \\
\hline PWT & 1.017 & {$[0.898,1.136]$} & 38 & 0.939 & {$[0.868,1.010]$} & 48 \\
WDI & 0.963 & {$[0.788,1.138]$} & 38 & 0.997 & {$[0.926,1.068]$} & 47 \\
\hline \hline \multicolumn{7}{c}{ OECD and UN Data } \\
\hline PWT & 1.079 & {$[0.972,1.185]$} & 35 & 0.925 & {$[0.849,1.001]$} & 44 \\
WDI & 1.056 & {$[0.874,1.238]$} & 35 & 0.990 & {$[0.933,1.046]$} & 42 \\
\hline Average & 1.029 & & 0.963 & & \\
\hline \hline
\end{tabular}

Notes: Column $\hat{\sigma}$ displays estimate of $\sigma$ from

$$
\frac{\bar{s}^{i}}{1-\bar{s}^{i}} \beta_{s}^{i}=\gamma+(\sigma-1)\left(\beta_{P}^{i}+\beta_{\zeta}^{i}\right)+\epsilon^{i}
$$

with $\beta_{P}^{i}+\beta_{\zeta}^{i}$ instrumented with $\beta_{P}^{i}$. Separate regressions estimated for each subset of countries, developed and emerging-market economies, where developed is defined by the UN based on its Human Development Index. Rows correspond to data set used to compute investment price trends. Top two rows use baseline hybrid measure of the labor share and bottom two use OECD/UN labor share series. All estimates include all countries for which investment prices and labor's share of income are available for at least $T_{\min }=10$ years. 
Table 8: Comparison of OECD vs. Non-OECD

\begin{tabular}{lcccccc}
\hline \hline & \multicolumn{3}{c}{ OECD } & \multicolumn{3}{c}{ Non-OECD } \\
\hline & $\hat{\sigma}$ & $90 \%$ C.I. & Obs. & $\hat{\sigma}$ & $90 \%$ C.I. & Obs. \\
\hline PWT & 1.044 & {$[0.914,1.174]$} & 34 & 0.939 & {$[0.869,1.008]$} & 52 \\
WDI & 0.940 & {$[0.637,1.242]$} & 35 & 0.996 & {$[0.926,1.067]$} & 50 \\
\hline \hline \multicolumn{6}{c}{ OECD and UN Data } \\
\hline PWT & 1.046 & {$[0.948,1.145]$} & 32 & 0.924 & {$[0.849,0.999]$} & 47 \\
WDI & 1.026 & {$[0.808,1.244]$} & 33 & 0.989 & {$[0.934,1.045]$} & 44 \\
\hline Average & 1.014 & & 0.962 & & \\
\hline \hline
\end{tabular}

Notes: Column $\hat{\sigma}$ displays estimate of $\sigma$ from

$$
\frac{\bar{s}^{i}}{1-\bar{s}^{i}} \beta_{s}^{i}=\gamma+(\sigma-1)\left(\beta_{P}^{i}+\beta_{\zeta}^{i}\right)+\epsilon^{i}
$$

with $\beta_{P}^{i}+\beta_{\zeta}^{i}$ instrumented with $\beta_{P}^{i}$. Separate regressions estimated for each subset of countries: those in the OECD and those that are not. Rows correspond to data set used to compute investment price trends. Top two rows use baseline hybrid measure of the labor share and bottom two use OECD/UN labor share series. All estimates include all countries for which investment prices and labor's share of income are available for at least $T_{\min }=10$ years. 
Table 9: Corporate Labor's Share Estimates

\begin{tabular}{c|ccc|ccc}
\hline \hline & \multicolumn{3}{|c}{ Only Corporate LS } & \multicolumn{3}{c}{ Baseline } \\
\hline & $\hat{\sigma}$ & $90 \%$ C.I. & Obs & $\hat{\sigma}$ & $90 \%$ C.I. & Obs \\
\hline PWT & 1.029 & {$[0.907,1.151]$} & 56 & 0.955 & {$[0.899,1.010]$} & 86 \\
WDI & 1.003 & {$[0.925,1.082]$} & 57 & 1.000 & {$[0.942,1.058]$} & 85 \\
\hline \multicolumn{7}{c}{ OECD and UN Data } \\
\hline PWT & 1.013 & {$[0.911,1.115]$} & 55 & 0.942 & {$[0.884,1.001]$} & 79 \\
WDI & 0.990 & {$[0.917,1.063]$} & 55 & 0.993 & {$[0.947,1.038]$} & 77 \\
\hline Average & 1.009 & & 1.009 & & & \\
\hline \hline
\end{tabular}

Notes: Column $\hat{\sigma}$ displays estimate of $\sigma$ from

$$
\frac{\bar{s}^{i}}{1-\bar{s}^{i}} \beta_{s}^{i}=\gamma+(\sigma-1)\left(\beta_{P}^{i}+\beta_{\zeta}^{i}\right)+\epsilon^{i}
$$

with $\beta_{P}^{i}+\beta_{\zeta}^{i}$ instrumented with $\beta_{P}^{i}$. Columns under "Only Corporate LS" use data on corporate labor's share of income alone, while columns under "Baseline" use the hybrid measure that substitutes economywide labor share whenever corporate is not available. Rows correspond to data set used to compute investment price trends. Top two rows use baseline hybrid measure of the labor share and bottom two use OECD/UN labor share series. All estimates include all countries for which investment prices and labor's share of income are available for at least $T_{\min }=10$ years. 
Table 10: Baseline vs. Real Interest Rate Specification

\begin{tabular}{c|ccc|ccc}
\hline \hline & \multicolumn{4}{|c}{ Baseline } & \multicolumn{3}{c}{ Interest Rate } \\
\hline & $\hat{\sigma}$ & $90 \%$ C.I. & Obs. & $\hat{\sigma}$ & $90 \%$ C.I. & Obs. \\
\hline PWT & 0.955 & {$[0.899,1.010]$} & 86 & 0.970 & {$[0.941,1.000]$} & 71 \\
WDI & 1.000 & {$[0.942,1.058]$} & 85 & 0.925 & {$[0.821,1.030]$} & 69 \\
\hline \hline \multicolumn{6}{c}{ OECD and UN Data } \\
\hline PWT & 0.942 & {$[0.884,1.001]$} & 79 & 0.964 & {$[0.934,0.994]$} & 65 \\
WDI & 0.993 & {$[0.947,1.038]$} & 77 & 0.933 & {$[0.807,1.059]$} & 62 \\
\hline Average & 0.973 & & 0.948 & & \\
\hline \hline
\end{tabular}

Notes: Column $\hat{\sigma}$ displays estimate of $\sigma$ from

$$
\frac{\bar{s}^{i}}{1-\bar{s}^{i}} \beta_{s}^{i}=\gamma+(\sigma-1)\left(\beta_{P}^{i}+\beta_{\zeta}^{i}\right)+\epsilon^{i}
$$

using real interest rates to calculate $\zeta_{t}^{i}$ instead of consumption growth, as in the baseline. We instrument $\beta_{P}^{i}+\beta_{\zeta}^{i}$ with $\beta_{P}^{i}$. Rows correspond to data set used to compute investment price trends. Top two rows use baseline hybrid measure of the labor share and bottom two use OECD/UN labor share series. All estimates include all countries for which investment prices and labor's share of income are available for at least $T_{\min }=10$ years. 
Table 11: Baseline vs. Robust Regression

\begin{tabular}{c|cc|cc|cc|c}
\hline \hline & \multicolumn{2}{|c}{ Baseline } & \multicolumn{3}{c}{ Bold } & \multicolumn{3}{c}{ Conservative } \\
\hline & $\hat{\sigma}$ & $90 \%$ C.I. & $\hat{\sigma}$ & $90 \%$ C.I. & $\hat{\sigma}$ & $90 \%$ C.I. & Obs. \\
\hline PWT & 0.955 & {$[0.899,1.010]$} & 0.996 & {$[0.957,1.035]$} & 0.992 & {$[0.951,1.034]$} & 86 \\
WDI & 1.000 & {$[0.942,1.058]$} & 1.012 & {$[0.978,1.045]$} & 1.003 & {$[0.967,1.040]$} & 85 \\
\hline \hline \multicolumn{7}{c}{ OECD and UN Data } \\
\hline PWT & 0.942 & {$[0.884,1.001]$} & 0.992 & {$[0.959,1.026]$} & 0.995 & {$[0.958,1.031]$} & 79 \\
WDI & 0.993 & {$[0.947,1.038]$} & 0.996 & {$[0.971,1.020]$} & 0.998 & {$[0.972,1.025]$} & 77 \\
\hline Average & 0.973 & & 0.999 & 0.996 & & \\
\hline \hline
\end{tabular}

Notes: Column $\hat{\sigma}$ displays estimate of $\sigma$ from

$$
\frac{\bar{s}^{i}}{1-\bar{s}^{i}} \beta_{s}^{i}=\gamma+(\sigma-1)\left(\beta_{P}^{i}+\beta_{\zeta}^{i}\right)+\epsilon^{i}
$$

using our baseline linear IV estimator. The columns "Bold" and "Conservative" estimate $\sigma$ from the above equation using robust regression as implemented in Stata, without instrumenting. Robust regression fits a sequence of weighted regressions to the data, iteratively re-weighting countries by their distance from the prediction line and dropping countries that are too far from the fitted relationship. Robust regression requires the user to specify a parameter governing how severely observations get down-weighted and dropped. The "Bold" columns correspond to heavily downweighting outliers while the "Conservative" columns down-weight less. Observations correspond to Baseline regression, some receive zero weight in the boldly tuned robust regression. Rows correspond to data set used to compute investment price trends. Top two rows use baseline hybrid measure of the labor share and bottom two use OECD/UN labor share series. All estimates include all countries for which investment prices and labor's share of income are available for at least $T_{\min }=10$ years. 


\subsection{Comparison with Previous Research}

We compare our estimates of $\sigma$ with those of KN and the IMF.

Table 12: Summary Statistics, KN Sample

\begin{tabular}{c|cccc}
\hline \hline & $\beta_{P}^{P W T}$ & $\beta_{\zeta}$ & $\beta_{P}^{P W T}+\beta_{\zeta}$ & $\beta_{P}^{P \widehat{W T}+} \beta_{\zeta}$ \\
\hline Mean & -0.55 & -0.28 & -0.83 & -0.83 \\
St. dev. & 1.33 & 2.05 & 2.64 & 1.70 \\
$\rho\left(\beta_{x}, \beta_{L S}\right)$ & 0.02 & 0.02 & 0.03 & 0.02 \\
$\rho\left(\beta_{x}, \beta_{P}^{P W T}\right)$ & 1.00 & 0.18 & 0.65 & 1.00 \\
\hline & $\beta_{P}^{W D I}$ & $\beta_{\zeta}$ & $\beta_{P}^{W D I}+\beta_{\zeta}$ & $\beta_{P}^{W D I}+\beta_{\zeta}$ \\
\hline Mean & -0.57 & -0.61 & -1.19 & -1.19 \\
St. dev. & 1.39 & 2.10 & 2.66 & 1.67 \\
$\rho\left(\beta_{x}, \beta_{L S}\right)$ & 0.24 & 0.20 & 0.28 & 0.24 \\
$\rho\left(\beta_{x}, \beta_{P}^{W D I}\right)$ & 1.00 & 0.13 & 0.63 & 1.00 \\
\hline \hline
\end{tabular}

Notes: Summary statistics for cross-sectional trends in prices and rental rate trends for PWT and WDI panels. Rows show mean, cross-sectional standard deviation, and correlations with labor share, and correlation with investment price trends alone. Statistics computed using the sample from KN, which is a subset of our sample in which all countries have at least $T_{\min }=15$ years of labor share and investment price data. 
Table 13: Comparison: Karabarbounis \& Neiman (2014)

\begin{tabular}{lccccccccccc}
\hline \hline & \multicolumn{2}{c}{ KN } & \multicolumn{1}{c}{ Include $\beta_{\zeta}^{i}$} & \multicolumn{3}{c}{ IV } & \multicolumn{2}{c}{$T_{\min }=10$} & \multicolumn{2}{c}{$T_{\min }=20$} \\
\hline & $\hat{\sigma}$ & S.E. & $\hat{\sigma}$ & S.E. & $\hat{\sigma}$ & S.E. & $\hat{\sigma}$ & S.E. & $\hat{\sigma}$ & S.E. \\
\hline PWT & $1.25^{\dagger}$ & $(0.08)$ & 1.09 & $(0.04)$ & 1.02 & $(0.08)$ & 1.03 & $(0.05)$ & 0.85 & $(0.17)$ \\
WDI & $1.29^{\dagger}$ & $(0.07)$ & 1.13 & $(0.04)$ & 1.15 & $(0.08)$ & 0.99 & $(0.05)$ & 1.10 & $(0.19)$ \\
\hline \hline \multicolumn{1}{c}{ OECD and UN Data } \\
\hline PWT & $1.20^{\dagger}$ & $(0.08)$ & 1.07 & $(0.04)$ & 0.97 & $(0.09)$ & 1.04 & $(0.04)$ & 0.75 & $(0.19)$ \\
WDI & $1.31^{\dagger}$ & $(0.06)$ & 1.14 & $(0.03)$ & 1.13 & $(0.08)$ & 0.97 & $(0.04)$ & 1.09 & $(0.34)$ \\
\hline Average & 1.26 & & 1.12 & & 1.07 & & 1.01 & & 0.95 & \\
\hline \hline
\end{tabular}

Notes: Columns $\hat{\sigma}$ displays estimate of $\sigma$ from

$$
\frac{\bar{s}^{i}}{1-\bar{s}^{i}} \beta_{s}^{i}=\gamma+(\sigma-1)\left(\beta_{P}^{i}+\beta_{\zeta}^{i}\right)+\epsilon^{i}
$$

using different estimators and samples. †The columns "KN" use the robust regression estimator with a bold tuning parameter and exactly match the estimates presented in KN and omits $\beta_{\zeta}^{i}$ when estimating the above equation. The column "Include $\beta_{\zeta}^{i}$ " uses the same robust regression estimator, but now includes $\beta_{\zeta}^{i}$. The column "IV" estimates the equation using two-stage least squares and instrumenting $\beta_{P}^{i}+\beta_{\zeta}^{i}$ with $\beta_{\zeta}^{i}$, but with the sample from $\mathrm{KN}$, which omits countries with fewer than $T_{\min }=15$ years of data. Columns " $T_{\min }=10$ " and " $T_{\min }=20$ " estimate the model with robust regression and omitting $\beta_{\zeta}^{i}$, but varying the number of years that each country must have data in order to be included in the sample. 
Table 14: Comparison: IMF WEO (2017)

\begin{tabular}{lcccc}
\hline \hline & \multicolumn{2}{c}{ IMF } & \multicolumn{2}{c}{ IV } \\
\hline & Estimate & S.E. & Estimate & S.E. \\
\hline All & -0.02 & $(0.03)$ & -0.01 & $(0.02)$ \\
Developed & 0.08 & $(0.03)$ & 0.04 & $(0.03)$ \\
Emerging & -0.05 & $(0.04)$ & -0.03 & $(0.02)$ \\
\hline \hline
\end{tabular}

Point estimates are reduced-form partial elasticities.

Notes: Columns labeled "Estimate" display estimates of $\gamma_{1}$ from

$$
\Delta s^{i}=\gamma_{0}+\gamma_{1}\left(\beta_{P}^{i}+\beta_{\zeta}^{i}\right)+\epsilon^{i}
$$

where $\Delta s^{i}$ is the total change in the labor share for country $i$. The columns under "IMF" omit $\beta_{\zeta}^{i}$ from the above equation, while the columns under "IV" instrument $\beta_{P}^{i}+\beta_{\zeta}^{i}$ with $\beta_{P}^{i}$. Separate regressions estimated for each subset of countries: developed and emerging-market economies, where developed is defined by the UN based on its Human Development Index. Rows correspond to data set used to compute investment price trends. Top two rows use baseline hybrid measure of the labor share and bottom two use OECD/UN labor share series. The sample is identical to that used by the IMF WEO (2017). 


\section{$9 \quad$ Figures}

These figures are referenced in each section.

\subsection{Simulation Figures}

Figure 1: Transition Path From Simulated Growth Model
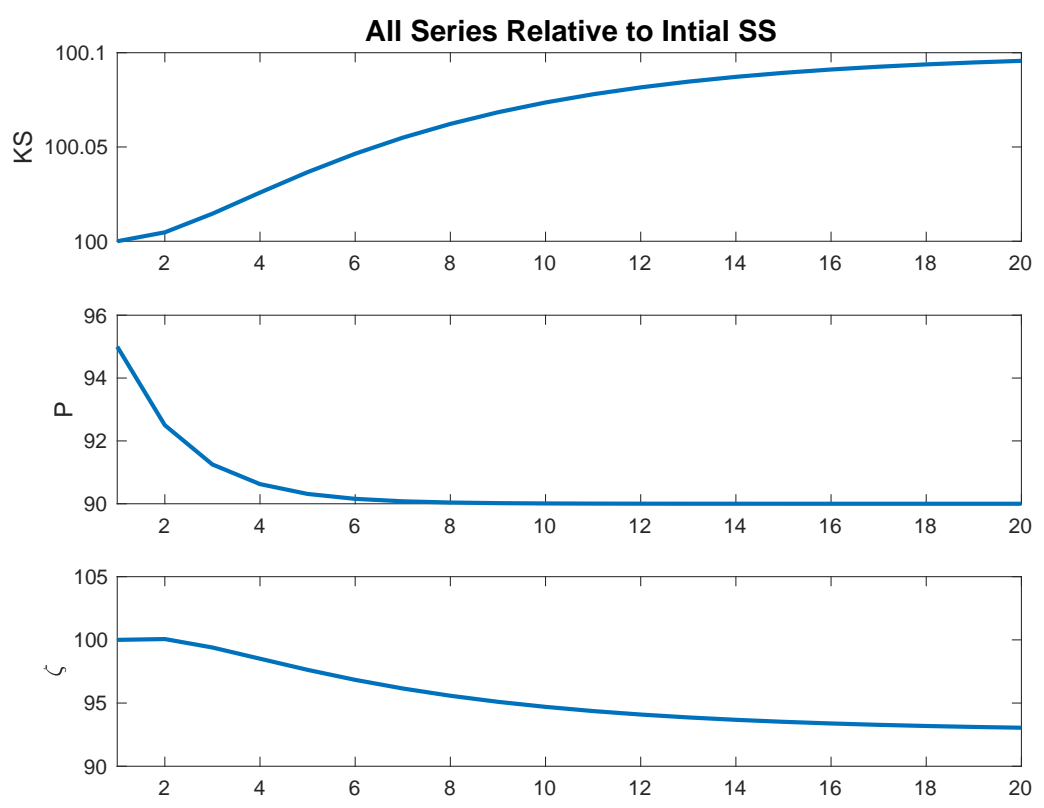

Notes: Simulated time series of capital's share of income ("KS"), investment prices ("P") and the term $\zeta_{t}$, which is the ratio of the rental rate of capital and investment price at $t$. Path of $P_{t}$ is chosen to eventually decline by $10 \%$. 
Figure 2: Upward Bias in Estimating $\sigma$ From Simulated Data

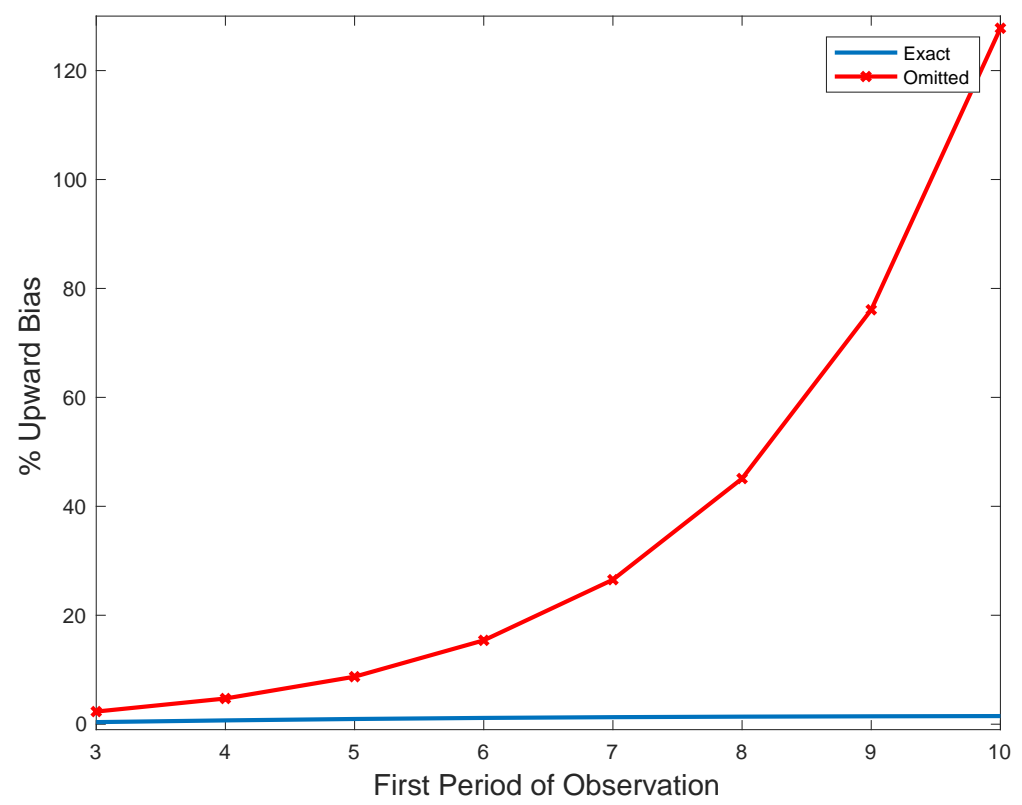

Notes: Upward bias from calculating $\sigma$ using the simulated series in Figure 1, with and without including the $\zeta$ term. Horizontal axis corresponds to first year of observation along transition path used to calculate the trend in each variable $\left(\beta_{1-s}, \beta_{P}, \beta_{\zeta}\right)$. Red hashed line displays $\hat{\sigma}_{o}=1-\frac{\beta_{1-s}}{\beta_{P}}$. Blue solid line displays $\hat{\sigma}_{e}=1-\frac{\beta_{1-s}}{\beta_{P}+\beta_{\zeta}}$. 


\subsection{Counterfactual Figures}

This figure shows the global changes in labor's share and investment prices as well as the predicted values.

Figure 3: Comparison of Predicted Global Labor's Share

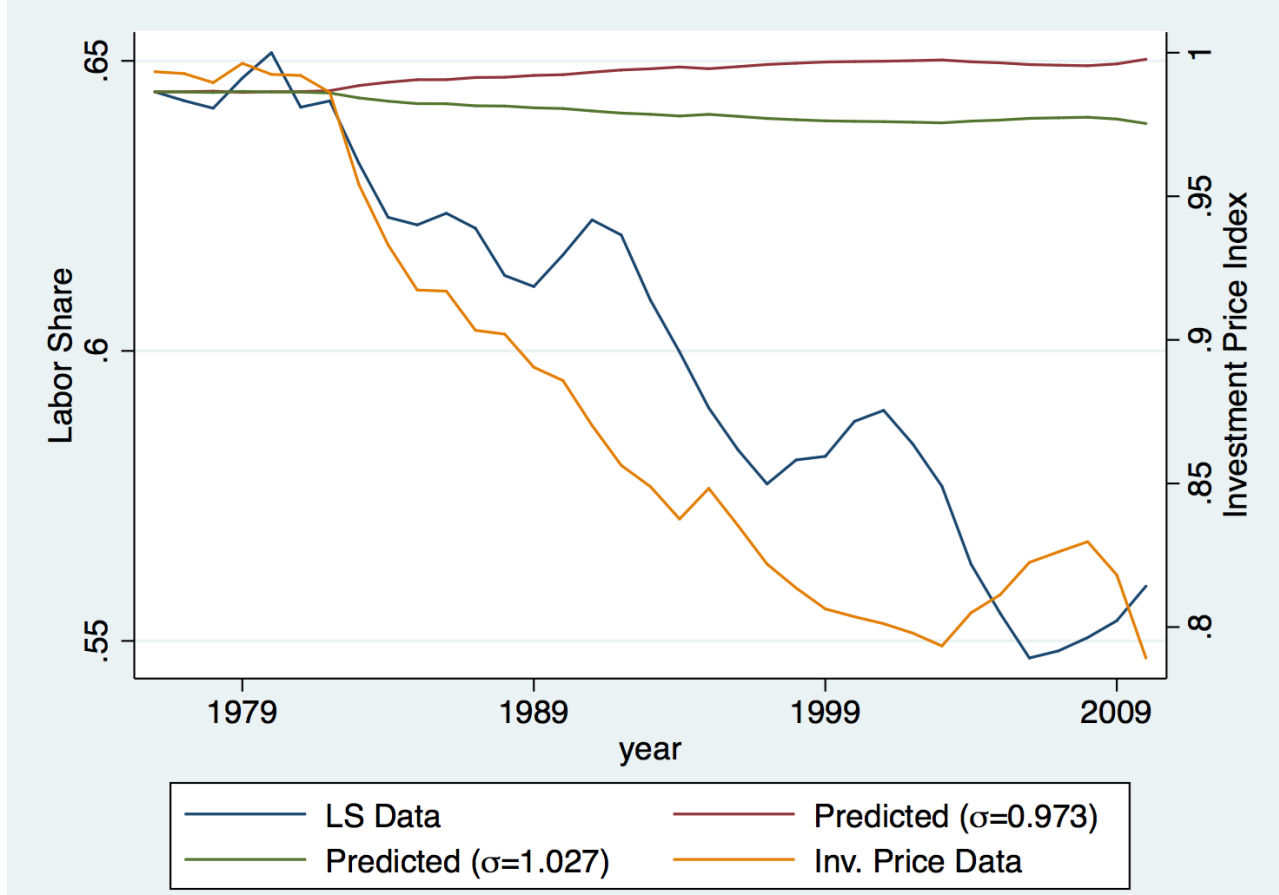

Notes: Displays empirical series for average global investment prices (lowest curve) and labor's share of income (curve above investment prices). Top two lines display predicted labor share series for both the average point estimates from our baseline regression $(\sigma=0.973)$ and the average upper bound of the $90 \%$ confidence intervals $(\sigma=1.027)$. 


\subsection{Point Estimates by Inclusion Threshold}

Figure 4: Estimates by Exclusion Criteria, $T_{\min }$

(a) PWT

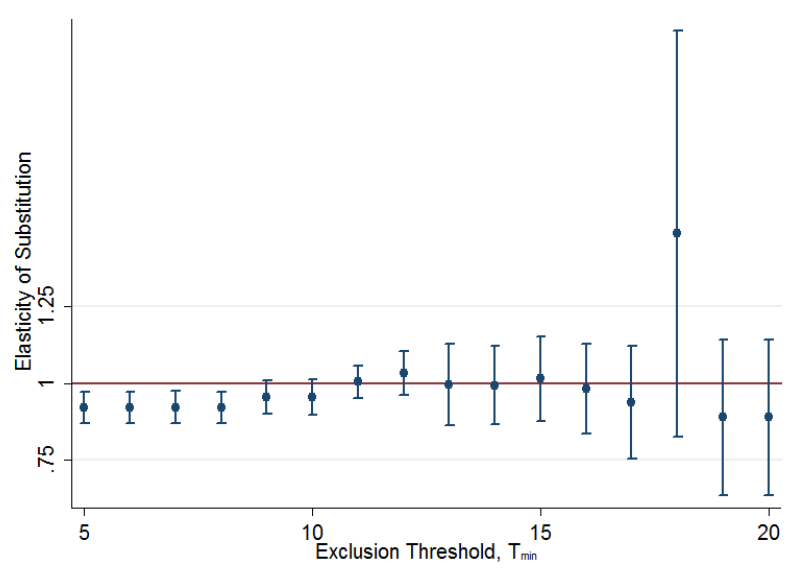

(c) PWT, OECD-UN ${ }^{\dagger}$

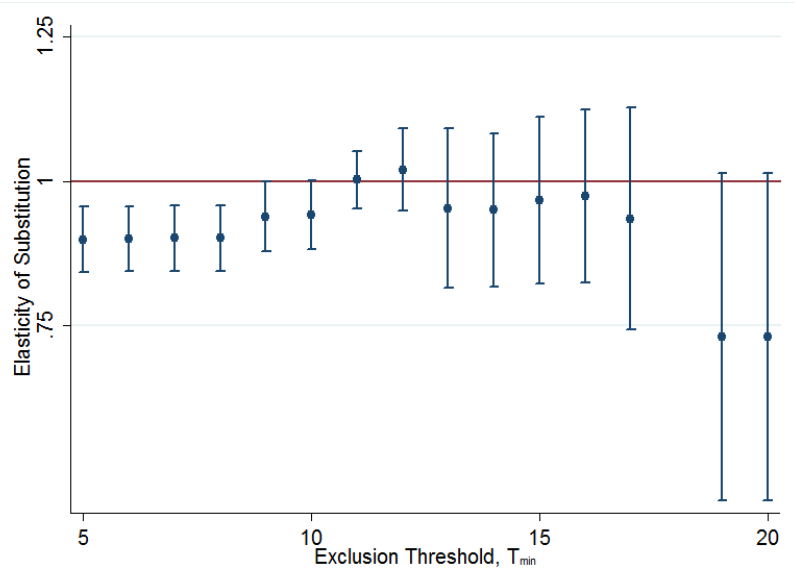

(b) $\mathrm{WDI}^{\dagger}$

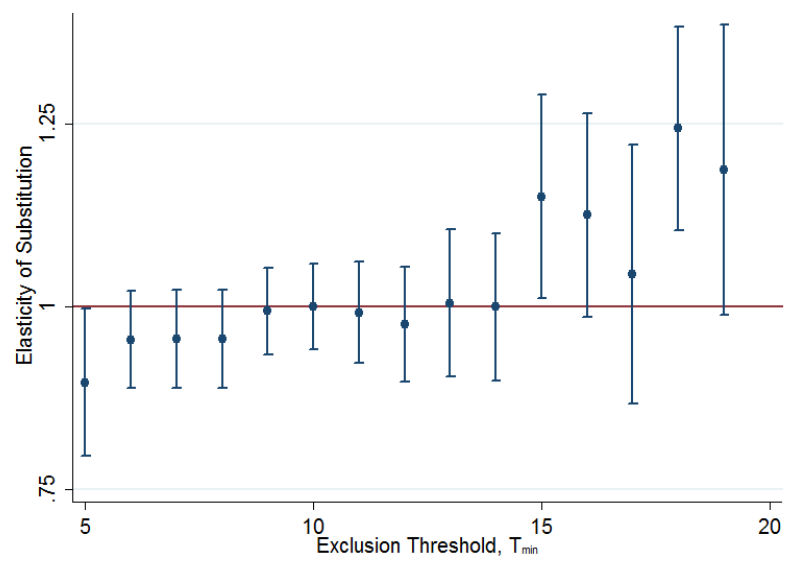

(d) WDI, OECD-UN

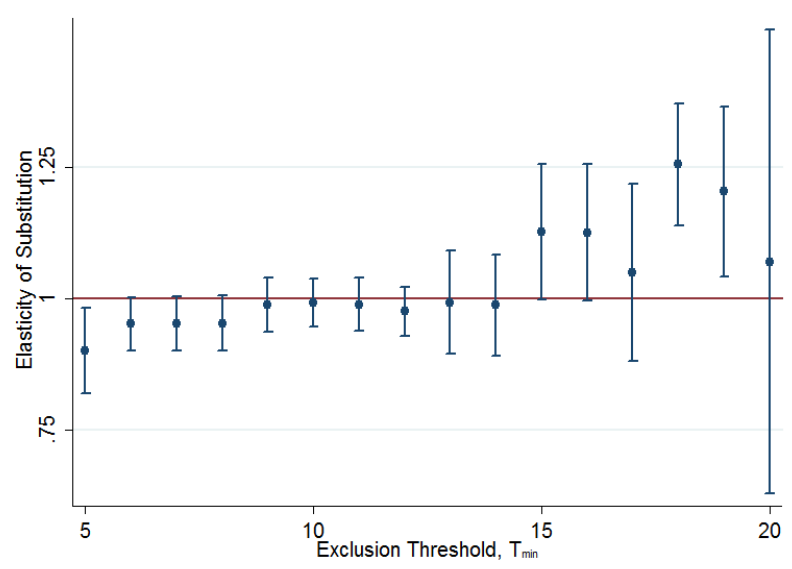

Notes: Point estimates and $90 \%$ confidence intervals for $\sigma$ estimated from

$$
\frac{\bar{s}^{i}}{1-\bar{s}^{i}} \beta_{s}^{i}=\gamma+(\sigma-1)\left(\beta_{P}^{i}+\beta_{\zeta}^{i}\right)+\epsilon^{i}
$$

with $\beta_{P}^{i}+\beta_{\zeta}^{i}$ instrumented by $\beta_{P}^{i}$. Horizontal axis displays exclusion threshold, $T_{m i n}$, used to construct sample: countries with fewer than $T_{\text {min }}$ years of data are dropped in each estimation.

${ }^{\dagger}$ Point estimates outside of the range $[0.5,1.5]$ but with standard errors greater than 0.5 are excluded to preserve scale. 


\section{A Estimating $\sigma$ with Markups}

This appendix is an extended robustness exercise to allow for market imperfections.

\section{A.1 Extending the Model}

We introduce exogenous, time-varying markups to the growth model by assuming that aggregate's profits are given by:

$$
\mu_{t}^{i} Y_{t}^{i}-w_{t}^{i} N_{t}^{i}-R_{t}^{i} K_{t}^{i}
$$

Where $\mu_{t}^{i}$ is the markup. These profits are then lump-sum rebated to households. The equilibrium is therefore as before, except that factor shares are given by:

$$
\begin{array}{r}
\mu_{t}^{i} L S_{t}^{i}=\left(1-\alpha_{k}\right)\left(Y_{t}^{i}\right)^{\frac{1-\sigma}{\sigma}} \\
\mu_{t}^{i} K S_{t}^{i}=\alpha_{k}\left(\frac{Y_{t}^{i}}{K_{t}^{i}}\right)^{\frac{1}{\sigma}} \\
P S_{t}^{i}=1-L S_{t}^{i}-K S_{t}^{i}=1-\frac{1}{\mu_{t}^{i}}
\end{array}
$$

Where the final equation defines profit's share of income. Notice that we are still assuming that labor is inelastically supplied, although this has no effect on our analysis.

\section{A.2 Empirical Model}

We first write capital's share to get a log-linear regression equation:

$$
1-\mu_{t}^{i} s_{t}^{i}=\left(\alpha_{k}^{i}\right)^{\sigma}\left(\frac{A_{t}^{i}}{\mu_{t}^{i} R_{t}^{i}}\right)^{\sigma-1}
$$

Taking the log difference from $t$ to $t+1$, assuming constant $A^{i}$, substituting for $R$, and approximating $\log \left(1-\mu_{t+1}^{i} s_{t+1}^{i}\right)$ around $\mu_{t+1}^{i}=m u_{t}^{i}$ and $s_{t+1}^{i}=s_{t}^{i}$ yields the estimating equation:

$$
\frac{\bar{\mu}^{i} \bar{s}^{i}}{1-\bar{\mu}^{i} \bar{s}^{i}}\left(\beta_{s}^{i}+\beta_{\mu}^{i}\right)=\mathrm{cons}+(\sigma-1)\left(\beta_{\mu}^{i}+\beta_{P}^{i}+\beta_{\zeta}^{i}\right)+\nu^{i}
$$

If we had time series for markups then we could estimate this model. We construct the average growth in markups in two stages. First we calculate the average level of markups and capital's share and then we impute the trend in these two variables using 
observable investment rates.

In order to calculate the averages, we will use the fact that capital's share can be written in terms of investment when the economy is in steady state as

$$
\frac{R^{i} K^{i}}{Y^{i}}=\frac{P^{i} X^{i}}{Y^{i}}\left(\frac{\frac{1}{\beta}+\delta-1}{\delta}\right)
$$

So, by assigning values to $\beta$ and $\delta$ and identifying the steady state as the average over of a variable, we know the capital's share for each country from

$$
\overline{K S}^{i}=\overline{\left(\frac{P^{i} X^{i}}{Y^{i}}\right)}\left(\frac{\frac{1}{\beta}+\delta-1}{\delta}\right)
$$

Labor's share is taken from the original data, so we can compute average markup from

$$
\bar{\mu}^{i}=\left(\overline{K S}^{i}+\overline{L S}^{i}\right)^{-1}
$$

This is still not enough to estimate $\sigma$; we need information on the average growth rate or trend in capital's share. We therefore consider an imputation proposed by KN, in which the trend in the capital's share is equated to the observed trend in the investment rate. That is, we will impute:

$$
\beta_{K S}^{i}=\beta_{I R}^{i}
$$

Where $I R_{t}^{i}=\frac{P_{t}^{i} X_{t}^{i}}{Y_{t}^{i}}$. This imputation may introduce substantial errors along a transition path, because the investment rate is not always monotonic, whereas capital's share is. With this caveat in mind, we can now compute

$$
\mu_{t}^{i}=\frac{1}{L S_{t}^{i}+K S_{t}^{i}}
$$

We then take the log differences of each side:

$$
\Delta \log \mu_{t+1}^{i}=-\Delta \log \left(L S_{t+1}^{i}+K S_{t+1}^{i}\right)
$$

We then approximate the right-hand side around $L S_{t+1}^{i}=L S_{t}^{i}$ and $K S_{t+1}^{i}=K S_{t}^{i}$ :

$$
\Delta \log \mu_{t+1} \approx-\left(\frac{L S_{t}^{i}}{L S_{t}^{i}+K S_{t}^{i}} \Delta \log L S_{t+1}^{i}+\frac{K S_{t}^{i}}{L S_{t}^{i}+K S_{t}^{i}} \Delta \log K S_{t+1}^{i}\right)
$$


And finally we replace levels with their averages and log differences with trends to get the imputed growth in the markup:

$$
\beta_{\mu}^{i} \approx-\left[\frac{\overline{L S^{i}}}{\overline{L S^{i}}+\overline{K S^{i}}} \beta_{L S}^{i}+\frac{\overline{L S^{i}}}{\overline{L S^{i}}+\overline{K S^{i}}} \beta_{K S}^{i}\right]
$$

This allows us to estimate $\sigma$ from Equation 32 .

\section{A.3 Estimation Results}

We present our estimation results in Table 15 for the four basic data sources and each exclusion restriction. We estimate only $\hat{\sigma}$ with robust regression because imputing markups introduces some extreme outliers. The estimates with markups are near one and most are below, with only one estimate significantly above one. The average across all estimates is $\hat{\sigma}=0.983$, which implies that investment prices cannot account for the global decline in labor's share. 
Table 15: Model with Markups Estimates

\begin{tabular}{lccc}
\hline \hline Hybrid, PWT & \multicolumn{3}{c}{ Exact } \\
\hline & $\hat{\sigma}$ & $90 \%$ Conf. Interval & Obs. \\
\hline$T_{\min }=10$ & 1.031 & {$[0.976,1.086]$} & 80 \\
$T_{\min }=15$ & 0.918 & {$[0.852,0.984]$} & 57 \\
\hline Corporate, PWT & & & \\
\hline$T_{\min }=10$ & 0.972 & {$[0.905,1.038]$} & 55 \\
$T_{\min }=15$ & 0.909 & {$[0.836,0.982]$} & 40 \\
\hline Hybrid, WDI & & & \\
\hline$T_{\min }=10$ & 1.056 & {$[1.012,1.100]$} & 81 \\
$T_{\min }=15$ & 1.017 & {$[0.935,1.099]$} & 54 \\
\hline Corporate, WDI & & & \\
\hline$T_{\min }=10$ & 0.990 & {$[0.921,1.058]$} & 52 \\
$T_{\min }=15$ & 0.969 & {$[0.875,1.063]$} & 38 \\
\hline Average & 0.983 & & \\
\hline \hline
\end{tabular}

